\title{
Geotechnical Characterization of TriNet Sites: A Status Report
}

\section{John Tinsley}

\author{
U.S. Geological Survey, Menlo Park
}

\section{Susan E. Hough and Alan Yong}

\author{
U.S. Geological Survey, Pasadena
}

\section{Hiroo Kanamori, Ellen Yu, and Vikki Appel}

\author{
California Institute of Technology
}

\section{Chris Wills}

California Geological Survey

\section{INTRODUCTION}

The TriNet project, launched in 1997, created an improved, real-time seismic monitoring network in Southern California. Planning of the network began in 1995 (e.g., Heaton et al., 1996), building on the success of the earlier TERRAscope network, which included 24 digital broadband and strongmotion instruments throughout Southern California (e.g., Kanamori et al., 1993). At the end of the five-year TriNet project the network comprised 150 real-time digital broadband stations and another 400 strong-motion sensors, 50 of which were also real-time. This network is now recording digital broadband data for Southern California earthquakes at an unprecedented rate, data that are already proving valuable for investigations of earthquake sources and regional wave propagation, as well as earthquake response.

In this report we describe an ongoing effort aimed at a full geotechnical characterization of the newly installed TriNet sets. Shallow geologic structure is known to play a substantial role in controlling the ground motions recorded at any site. Documentation of amplified ground motion at soft-sediment sites can be found among even early macroseismic observations of strong ground motions (e.g., Drake, 1815). Seismic waves are also now known to be strongly affected by deep basin structure as well (e.g., Frankel et al., 1991; Field, 2000; Joyner, 2000). It will be necessary to understand these effects to exploit fully the rich data set being recorded at TriNet sites. Clearly, the nature of site conditions and site response at the recording sites must be understood for studies focused on ground motions and hazard from future large earthquakes, but it is also necessary to understand these effects to conduct earthquake source studies of both large and small earthquakes.
Our multifaceted site characterization project involves geological/geotechnical site investigations, database development, and investigation of empirical amplification factors determined from broadband and strong-motion data recorded to date. Our goal is to complete a first-order geologic site characterization by 2005 and then employ appropriate methods to obtain direct constraint on shallow shearwave velocity structure at each site. In the latter effort we will endeavor to find the most accurate and cost-effective methods to quantify geotechnical parameters at sites that have ranges of geologic site conditions and cultural settings.

Our long-term goal is to obtain direct estimates of the average shear-wave velocity in the upper $30 \mathrm{~m}$, Vs30, at each site. If velocity information is available to greater depths, for example at sites characterized under the ROSRINE project (http://geoinfo.usc.edu/rosrine/), this information will be included in the database as well. The original motivation for using Vs30 to characterize near-surface velocity was pragmatic, determined by such factors as the typical reach of a drill rig in a single day. The parameter has become the accepted standard with which many seismic recording sites are characterized, however. In a recent study using mainshock and aftershock recordings at sites in the Los Angeles region, Wald and Mori (2000) observed good correlation between Vs30 and amplification at $1-7 \mathrm{~Hz}$, albeit with significant scatter.

The purpose of this report is threefold. First, we describe our ongoing efforts and present site characterization results collected to date for 62 broadband and strong-motion stations in and around the greater Los Angeles metropolitan region. Second, we present preliminary results that illustrate how improved geologic site characterizations can improve the 
correlation between site conditions and site response. Finally, we invite feedback from the community to guide our future investigations, in particular with respect to our ongoing database development efforts.

\section{SITE CHARACTERIZATION}

In the absence of field surveys or direct measurements, a recent map published by Wills et al. (2000) based on the 1:250,000-scale Geologic Map of California can be used to assign "first cut" site conditions at any location in California. This map includes the standard NEHRP site classes, A-E, as well as intermediate classes (Wills et al., 2000). The map does not include geologic data at sufficiently fine scale to estimate site conditions at specific locations, however; this approach to site characterization represents a misuse of the map. Wills et al. (2000) state that such assignments are expected to have substantial error. One might further imagine that the misclassification rate for seismic stations could be even higher because the sites are typically not chosen randomly. For example, a site might be located on an isolated hard-rock outcrop in the midst of an alluvial area. As a first cut, however, site classes at all of the TriNet sites are determined from the Wills et al. (2000) map. (In this report we will use the term "site classes" to refer generically to classifications that do not coincide with the NEHRP classes as originally defined.)

The second step involves surveying each site and determining site class based on a generalized geologic assessment. In our first year of the project we focused on 62 sites in and around the greater Los Angeles metropolitan region, sites that are of prime concern for ground motion and hazard studies. Such investigations are aided significantly by numerous previous studies that have established shallow shear-wave velocities for many of the common sedimentary formations found in Southern California. At some sites we have estimated not only site class but also Vs30, as discussed below.

Site visits were conducted using an informal "blind geologist" protocol, which is to say that a well sighted geologist (to date, John Tinsley) evaluated each site without prior knowledge of site classification or site response information. Locating the sensor at each site, a site classification was assigned based on a visual assessment of geologic conditions. This evaluation drew on not only general consideration of geologic and geomorphic conditions but also on familiarity, based on years of prior work in the area (e.g., Gibbs et al., 1999; Gibbs et al., 2000), with basin structure, common regional geologic units, and existing subsurface data.

Where site conditions could not be readily evaluated because of structures or pavement, the field teams examined the closest exposed materials. Visits seldom required more than 10-15 minutes. The seismologist (usually Hough) would make notes of Tinsley's observations and site classifications, and note the mode(s) of in situ investigation considered most appropriate for determining site-specific measurement of Vs30 and/or site class determination in future years. As we will discuss, in almost every instance where there was a discrepancy between the Wills et al. (2000) map-based determination and Tinsley's assigned classification, the adoption of Tinsley's guess improves the overall correlation between site geology and amplification.

We visited 58 sites and were able to obtain site characterization results for an additional four sites from previous drill results under the ROSRINE project. Drilling results were also available for station RSS, installed under the University of California earthquake program (Heuze et al., 2002), as well as several stations investigated in past U.S. Geological Survey studies (Gibbs et al., 1999; Gibbs et al., 2000). The Vs30 values listed were calculated from the borehole measurements by Boore (personal communication). These investigations resulted in changes of site classifications at 19 of the 62 sites (Table 1). At an additional four sites we determined an intermediate site class (e.g., BC-C) based on estimated Vs30 values that do not fall squarely within the expanded site classifications of Wills et al. (2000). We do not suggest that an expanded classification scheme should be adopted, but rather use the intermediate assignments as a proxy for Vs30. Where Vs30 values are known or estimated, they can be used to assign site classification according to either the standard NEHRP definitions or the expanded definitions defined by Wills et al. (2000).

In addition to determining the site classes, we were also able to estimate Vs30 values for some stations based on prior knowledge of rock units. At eight sites we performed seismic cone penetrometer testing (SCPT); these provided projected Vs30 estimates at four sites (LAF, LTP, MLS, STG). At one station (MLS) the SCPT data yielded a new site classification. The map-based classification of this site was $\mathrm{D}$, the field assessment was D-CD, and the SCPT classification was CD. At the other three sites the SCPT results were consistent with the "Tinsley" assignment and provided refined estimates of Vs30. We estimated Vs30 values at an additional 13 stations, including stations for which the site classification both was and was not changed. Overall, our field surveys and initial SCPT investigations resulted in a revised site class or refined Vs30 estimates at nearly half of the stations: 30 out of 62 . Table 1 indicates those sites for which we have either SCPT results or prior drilling results. The other stations for which Vs30 is included are sites at which the values are estimated based on prior knowledge of rock unit.

Although most of our reclassifications were based on subjective assessments rather than direct measurements, our analysis of empirical site response (discussed below) supports the validity of such field-based determinations. In the greater Los Angeles region especially, such an approach draws on decades of previous work to characterize the geotechnical properties of geologic units. In any area, however, such field investigations will be useful to correct misassignments that result from the coarse scale of any regional map. Ultimately, our goal is that all subjective determinations will be replaced by direct measurements. 
TABLE 1
Greater Los Angeles Stations

\begin{tabular}{|c|c|c|c|c|c|c|c|c|c|c|c|c|}
\hline Station & Lat. & Long. & $A(3)$ & $\operatorname{sd}(3)$ & $A(1)$ & $\operatorname{sd}(1)$ & $A(0.3)$ & $\operatorname{sd}(0.3)$ & $\boldsymbol{N}$ & $S_{m}$ & $\boldsymbol{S}_{g}$ & Vs30 \\
\hline ago & $34.146^{\circ}$ & $118.767^{\circ}$ & 0.225 & 0.248 & 0.368 & 0.176 & 0.568 & 0.139 & 15 & $D$ & $B C-C$ & 660 \\
\hline bre & $33.810^{\circ}$ & $117.982^{\circ}$ & 0.671 & 0.241 & 0.594 & 0.186 & 0.530 & 0.200 & 40 & $D$ & $D$ & \\
\hline cal & $34.140^{\circ}$ & $118.628^{\circ}$ & NA & NA & NA & NA & NA & NA & NA & D & D & \\
\hline chn & $33.999^{\circ}$ & $117.680^{\circ}$ & 0.478 & 0.171 & 0.475 & 0.198 & 0.539 & 0.225 & 54 & D & D & 315 \\
\hline clt & $34.093^{\circ}$ & $117.317^{\circ}$ & 0.499 & 0.180 & 0.581 & 0.197 & 0.726 & 0.217 & 52 & $C D$ & $C D$ & \\
\hline cpp & $34.060^{\circ}$ & $117.809^{\circ}$ & 0.217 & 0.250 & 0.659 & 0.246 & 0.613 & 0.231 & 117 & D & $\mathrm{D}$ & \\
\hline crn & $33.876^{\circ}$ & $117.561^{\circ}$ & 0.169 & 0.285 & 0.125 & 0.253 & 0.488 & 0.207 & 40 & $C D$ & $C D$ & \\
\hline dec & $34.254^{\circ}$ & $118.334^{\circ}$ & 0.168 & 0.152 & 0.376 & 0.186 & 0.551 & 0.168 & 42 & C & B & \\
\hline dgr & $33.650^{\circ}$ & $117.009^{\circ}$ & -0.113 & 0.206 & -0.100 & 0.244 & 0.159 & 0.265 & 93 & $\mathrm{BC}$ & $\mathrm{BC}^{\star \star}$ & \\
\hline $\mathrm{djj}$ & $34.106^{\circ}$ & $118.454^{\circ}$ & -0.011 & 0.197 & 0.032 & 0.223 & 0.202 & 0.211 & 75 & $C$ & $B C-C^{\star}$ & 673 \\
\hline fmp & $33.713^{\circ}$ & $118.294^{\circ}$ & 0.090 & 0.157 & 0.241 & 0.172 & 0.150 & 0.205 & 42 & $C D$ & $C$ & 600 \\
\hline fon & $34.100^{\circ}$ & $117.439^{\circ}$ & 0.229 & 0.093 & 0.327 & 0.201 & 0.423 & 0.219 & 32 & $C D$ & $C D$ & 315 \\
\hline ful & $33.872^{\circ}$ & $117.923^{\circ}$ & 0.665 & 0.204 & 0.694 & 0.217 & 0.676 & 0.197 & 26 & $D$ & D & \\
\hline gr2 & $34.118^{\circ}$ & $118.299^{\circ}$ & 0.038 & 0.144 & 0.260 & 0.193 & 0.569 & 0.189 & 81 & $B C$ & $B^{*}$ & 958 \\
\hline gsa & $34.137^{\circ}$ & $118.128^{\circ}$ & 0.189 & 0.053 & 0.410 & 0.179 & 0.546 & 0.257 & 13 & $C D$ & $C D$ & \\
\hline hll & $34.176^{\circ}$ & $118.360^{\circ}$ & 0.334 & 0.192 & 0.482 & 0.183 & 0.389 & 0.185 & 49 & $D$ & $C D^{*}$ & 333 \\
\hline hln & $34.121^{\circ}$ & $117.219^{\circ}$ & 0.286 & 0.252 & 0.420 & 0.265 & 0.392 & 0.294 & 25 & $C D$ & $C D$ & \\
\hline kik & $34.150^{\circ}$ & $118.102^{\circ}$ & 0.397 & 0.210 & 0.450 & 0.208 & 0.436 & 0.206 & 21 & $C D$ & $C D$ & \\
\hline laf & $33.869^{\circ}$ & $118.331^{\circ}$ & 0.607 & 0.191 & 0.465 & 0.181 & 0.476 & 0.141 & 52 & $C D$ & $C D-D$ & 296 \\
\hline$|k|$ & $34.616^{\circ}$ & $117.824^{\circ}$ & 0.027 & 0.250 & 0.107 & 0.238 & 0.766 & 0.224 & 113 & D & D & \\
\hline lbw2 & $33.798^{\circ}$ & $118.088^{\circ}$ & 0.605 & 0.223 & 0.633 & 0.297 & 0.707 & 0.228 & 6 & $D$ & $D^{*}$ & 190 \\
\hline $\operatorname{lcg}$ & $34.000^{\circ}$ & $118.378^{\circ}$ & 0.575 & 0.206 & 0.401 & 0.164 & 0.441 & 0.155 & 54 & $C D$ & $C D$ & \\
\hline Ifp & $34.305^{\circ}$ & $118.488^{\circ}$ & 0.372 & 0.151 & 0.516 & 0.232 & 0.566 & 0.198 & 54 & $D$ & $D$ & 315 \\
\hline $\lg b$ & $33.976^{\circ}$ & $118.149^{\circ}$ & 0.532 & 0.200 & 0.436 & 0.151 & 0.458 & 0.183 & 47 & $D$ & D & \\
\hline Igu & $34.108^{\circ}$ & $119.066^{\circ}$ & -0.084 & 0.220 & 0.006 & 0.228 & 0.516 & 0.210 & 58 & $C D$ & B & 880 \\
\hline \|s & $33.685^{\circ}$ & $117.943^{\circ}$ & 0.523 & 0.182 & 0.558 & 0.170 & 0.725 & 0.201 & 50 & $D$ & D & \\
\hline Itp & $33.881^{\circ}$ & $118.176^{\circ}$ & 0.612 & 0.221 & 0.601 & 0.164 & 0.690 & 0.184 & 43 & $D$ & D & 232 \\
\hline mis & $33.740^{\circ}$ & $118.335^{\circ}$ & NA & NA & NA & NA & NA & NA & $N A$ & $C D$ & C & \\
\hline $\mathrm{mls}$ & $34.005^{\circ}$ & $117.561^{\circ}$ & -0.079 & 0.204 & 0.334 & 0.228 & 0.542 & 0.246 & 89 & $D$ & $C D$ & 345 \\
\hline mop & $34.281^{\circ}$ & $118.905^{\circ}$ & 0.457 & 0.170 & 0.750 & 0.180 & 0.608 & 0.161 & 55 & $D$ & $D$ & \\
\hline not & $34.229^{\circ}$ & $118.558^{\circ}$ & 0.735 & 0.207 & 0.803 & 0.222 & 0.851 & 0.204 & 24 & $D$ & D & \\
\hline $\mathrm{ogc}$ & $33.788^{\circ}$ & $117.844^{\circ}$ & 0.546 & 0.218 & 0.522 & 0.205 & 0.637 & 0.213 & 29 & $D$ & $C D$ & 315 \\
\hline oli & $33.946^{\circ}$ & $117.924^{\circ}$ & -0.299 & 0.217 & 0.362 & 0.226 & 0.444 & 0.217 & 53 & $C D$ & $C D$ & \\
\hline osi & $34.614^{\circ}$ & $118.724^{\circ}$ & 0.091 & 0.211 & 0.267 & 0.182 & 0.162 & 0.209 & 85 & $C D$ & $B C-C$ & 600 \\
\hline pas & $34.148^{\circ}$ & $118.171^{\circ}$ & -0.012 & 0.187 & 0.013 & 0.214 & 0.018 & 0.227 & 112 & $\mathrm{BC}$ & $\mathrm{B}^{\star \star}$ & \\
\hline pde & $34.442^{\circ}$ & $118.582^{\circ}$ & 0.409 & 0.153 & 0.431 & 0.172 & 0.603 & 0.177 & 57 & $C$ & C & \\
\hline \multicolumn{13}{|c|}{$\begin{array}{l}\text { Columns: station name; latitude; longitude; estimated amplification factor and standard deviation from the east-west component at 3, 1, and } 0.3 \mathrm{~s} \\
\text { (NA: amplification factors not available); number of earthquakes used in regression; site class estimated from Wills et al. map; site class estimatec } \\
\text { from general geologic assessment (single asterisk indicates estimate from ROSRINE or other drilling results, double asterisk indicates relatively } \\
\text { uncertain estimate due to absence of direct measurements); estimate of Vs30, if available. }\end{array}$} \\
\hline
\end{tabular}




\begin{tabular}{|c|c|c|c|c|c|c|c|c|c|c|c|c|}
\hline \multicolumn{13}{|c|}{$\begin{array}{c}\text { TABLE } 1 \text { (Continued) } \\
\text { Greater Los Angeles Stations }\end{array}$} \\
\hline Station & Lat. & Long. & $A(3)$ & $\operatorname{sd}(3)$ & $A(1)$ & $\operatorname{sd}(1)$ & $A(0.3)$ & $\operatorname{sd}(0.3)$ & $N$ & $S_{m}$ & $S_{g}$ & Vs30 \\
\hline pdr & $33.963^{\circ}$ & $118.437^{\circ}$ & 0.652 & 0.240 & 0.495 & 0.170 & 0.352 & 0.138 & 20 & $C D$ & $C D$ & \\
\hline pdu & $34.121^{\circ}$ & $117.638^{\circ}$ & 0.131 & 0.167 & 0.210 & 0.175 & 0.323 & 0.208 & 57 & $C D$ & C & \\
\hline qug & $34.396^{\circ}$ & $118.499^{\circ}$ & 0.459 & 0.238 & 0.527 & 0.205 & 0.433 & 0.161 & 5 & $C D$ & C & \\
\hline rin & $34.282^{\circ}$ & $118.479^{\circ}$ & 0.134 & 0.480 & 0.150 & 0.538 & 0.155 & 0.579 & 32 & C & $C D^{*}$ & 333 \\
\hline rio & $34.105^{\circ}$ & $117.980^{\circ}$ & 0.370 & 0.229 & 0.325 & 0.156 & 0.331 & 0.191 & 49 & D & $C D-C$ & 420 \\
\hline rpv & $33.743^{\circ}$ & $118.404^{\circ}$ & 0.196 & 0.218 & 0.404 & 0.205 & 0.516 & 0.213 & 101 & C & C & \\
\hline rss & $33.973^{\circ}$ & $117.327^{\circ}$ & -0.116 & 0.225 & -0.025 & 0.235 & 0.591 & 0.195 & 57 & B & $C D-C^{*}$ & 460 \\
\hline rus & $34.050^{\circ}$ & $118.080^{\circ}$ & 0.576 & 0.197 & 0.526 & 0.160 & 0.515 & 0.213 & 86 & D & D & \\
\hline rvr & $33.993^{\circ}$ & $117.376^{\circ}$ & -0.054 & 0.213 & -0.137 & 0.231 & 0.054 & 0.245 & 108 & $C D$ & B & \\
\hline $\operatorname{san}$ & $33.704^{\circ}$ & $117.886^{\circ}$ & 0.544 & 0.161 & 0.481 & 0.207 & 0.661 & 0.371 & 25 & D & D & \\
\hline sdd & $33.553^{\circ}$ & $117.662^{\circ}$ & 0.485 & 0.191 & 0.574 & 0.198 & 0.479 & 0.194 & 48 & $C D$ & $C D$ & \\
\hline ses & $34.437^{\circ}$ & $119.138^{\circ}$ & 0.493 & 0.210 & 0.489 & 0.167 & 0.264 & 0.187 & 39 & $C D$ & $\mathrm{CD}$ & \\
\hline sio & $34.293^{\circ}$ & $119.165^{\circ}$ & 0.643 & 0.291 & 0.632 & 0.260 & 0.440 & 0.317 & 6 & $C D$ & CD-D & 315 \\
\hline sju & $33.487^{\circ}$ & $117.681^{\circ}$ & 0.647 & 0.188 & 0.576 & 0.256 & 0.593 & 0.264 & 23 & D & D & \\
\hline sms & $34.015^{\circ}$ & $118.456^{\circ}$ & 0.625 & 0.199 & 0.517 & 0.201 & 0.505 & 0.203 & 99 & $C D$ & $C D$ & \\
\hline smv & $34.271^{\circ}$ & $118.744^{\circ}$ & 0.448 & 0.182 & 0.715 & 0.200 & 0.691 & 0.217 & 14 & $D$ & D & \\
\hline spf & $34.059^{\circ}$ & $118.646^{\circ}$ & -0.002 & 0.133 & 0.226 & 0.157 & 0.242 & 0.149 & 40 & C & $B C$ & \\
\hline srn & $33.828^{\circ}$ & $117.789^{\circ}$ & 0.289 & 0.174 & 0.296 & 0.209 & 0.357 & 0.221 & 50 & $\mathrm{CD}$ & C & \\
\hline stc & $34.303^{\circ}$ & $119.187^{\circ}$ & 0.617 & 0.203 & 0.467 & 0.188 & 0.538 & 0.179 & 55 & C & $C D-C$ & 460 \\
\hline stg & $33.664^{\circ}$ & $117.769^{\circ}$ & 0.146 & 0.164 & 0.339 & 0.224 & 0.433 & 0.216 & 52 & D & D & 309 \\
\hline sts & $33.790^{\circ}$ & $118.199^{\circ}$ & 0.543 & 0.154 & 0.523 & 0.156 & 0.621 & 0.170 & 63 & $E$ & D & \\
\hline svd & $34.107^{\circ}$ & $117.098^{\circ}$ & 0.060 & 0.206 & 0.124 & 0.217 & 0.353 & 0.232 & 108 & $B C$ & $B C$ & \\
\hline tov & $34.156^{\circ}$ & $118.820^{\circ}$ & 0.242 & 0.212 & 0.331 & 0.183 & 0.087 & 0.173 & 88 & C & $B C$ & \\
\hline USC & $34.019^{\circ}$ & $118.286^{\circ}$ & 0.530 & 0.203 & 0.427 & 0.175 & 0.405 & 0.193 & 101 & D & D & \\
\hline wit & $34.010^{\circ}$ & $117.951^{\circ}$ & 0.571 & 0.237 & 0.685 & 0.158 & 0.604 & 0.204 & 55 & D & D & \\
\hline wSs & $34.172^{\circ}$ & $118.650^{\circ}$ & 0.346 & 0.227 & 0.569 & 0.248 & 0.815 & 0.287 & 36 & $C D$ & C & \\
\hline wtt & $33.949^{\circ}$ & $118.255^{\circ}$ & 0.587 & 0.187 & 0.521 & 0.194 & 0.622 & 0.180 & 48 & D & $\mathrm{D}$ & \\
\hline $\begin{array}{l}\text { Columr } \\
\text { (NA: an } \\
\text { from ge }\end{array}$ & $\begin{array}{l}\text { ation nam } \\
\text { cation fac } \\
\text { geologic }\end{array}$ & $\begin{array}{l}\text { רe; latitude; } \\
\text { tors not avai } \\
\text { assessmen }\end{array}$ & $\begin{array}{l}\text { iitude; } \\
\text { le); nur } \\
\text { ingle as }\end{array}$ & $\begin{array}{l}\text { רated } \\
\text { of ea } \\
\text { k ind }\end{array}$ & ification & or and & רdard d & $\begin{array}{l}\text { tion fro } \\
\text { estime } \\
\text { drilling }\end{array}$ & eas & com & $\begin{array}{l}\text { at } 3,1 \\
\text { ite clas } \\
\text { licates }\end{array}$ & $\begin{array}{l}\text { nd } 0.3 \mathrm{~s} \\
\text { estimate } \\
\text { latively }\end{array}$ \\
\hline
\end{tabular}

\section{DATABASE}

A critical part of the site characterization project will involve development of a database, with a Web-based interface, through which all of the results will be freely available. One of our challenges will be to design the database to be sufficiently flexible to include diverse site characterization data, ranging from map-based site classifications to quantitative results from direct measurements. Our goal for the database is that it will include the best available data at each site and, at a minimum, a site classification using the expanded definitions of Wills et al. (2000). Although initially some of the values will be map-based, our hope is to replace all of these with values determined by geologic survey by the end of 2005 .

The site characterization database will include velocity data, image files, and tables of CPT logs. It will also include links to existing sources of information. The database will facilitate common queries such as showing all stations with a specified site class, all earthquakes recorded at stations with a given site class, etc. 


\section{AMPLIFICATION FACTORS}

Since its inception, TriNet has recorded data that have been used to obtain increasingly robust estimates of magnitudes of earthquakes in Southern California (Kanamori et al., 1993). As part of the TriNet effort, the station corrections for local magnitude, $M_{L}$, as well as the site amplification factors at periods of $0.3,1.0$, and 3.0 seconds are routinely determined by regressions of large volumes of data. To calculate the amplification factors in these pass-bands, the amplitude data (displacement) for each channel are band-pass filtered over frequency bands of $0.233-0.433,0.7-1.3$, and $2-4 \mathrm{~Hz}$, respectively. The peak amplitude is determined within each pass-band. The envelopes of the filtered seismograms are observed to be very smooth, so the peak amplitude provides a stable estimate of overall amplitude. The amplitude at the $i$ th station of the $j$ th earthquake is represented by

$a_{i j}=a_{0 j} s_{i} r_{i} j^{n} \exp \left(-k r_{i j}\right)$.

Here, $r_{i j}$ is the hypocentral distance for each event-station pair, $a_{0 j}$ is the amplitude at a reference station, $s_{i}$ is the station amplification factor, and $n$ and $k$ are constants that reflect geometrical spreading and attenuation. Taking the logarithm of Equation 1 we obtain

$$
\log \left(a_{i j}\right)=\log \left(a_{0 j}\right)+\log \left(s_{i}\right)-n \log \left(r_{i} j\right)+\log (e)\left(-k r_{i j}\right) .
$$

Given a set of $M$ earthquakes and $N$ sites, one can invert for $k, n, N s_{i}$ terms, and $M a_{0 j}$ terms. This becomes impractical for large $N$ and $M$, however, so an alternative procedure is to solve the following equation:

$$
\log \left(a_{i j}\right)=\log \left(a_{0 j}\right)-n \log \left(r_{i} j\right)+\log (e)\left(-k r_{i j}\right)
$$

for $n, k$, and $M a_{0 j}$ terms. The $s_{i}$ terms, which are the focus of this study, are then assumed to be the average residual at each station, computed by normalizing amplitudes using PAS as the reference station. The values of $n$ are found to be 1.0, 0.81 , and 0.90 for the 3-, 1-, and 0.3-s band, respectively. The values of $k$ are, respectively, $0.0009,0.0046$, and $0.0076 \mathrm{~km}^{-1}$.

After solving for unknown amplitudes across the network and overall optimal path terms, the inversion yields average residuals and rms misfit at all stations at the three periods. These values, which represent the "leftovers" of the magnitude determinations, presumably reflect path-dependent propagation effects and/or site response. They are estimated for the three periods of engineering concern.

Previous studies do suggest a more complicated crustal attenuation structure than can be captured by the path terms assumed (e.g., Ho-Liu et al., 1988), but assuming such effects are relatively minor compared to site response, one is left with an extensive collection of observational results with which to investigate site and basin response at TriNet sites. These "amplification factors" will presumably reflect the full range of site effects, including shallow-layer resonances, large-scale basin effects (e.g., Frankel et al., 1991), and near-site attenuation (e.g., Anderson and Hough, 1984).

Compared to the numbers of earthquakes and sites that have been used in previous site response studies, as well as the frequency bandwidth, the TriNet results represent a unique opportunity to investigate key remaining issues in groundmotion studies. These include: What is the degree of eventto-event variability in site response? Can one observe azimuthal variability in site response for sites in large basins or valleys? Does the sometimes poor general correlation between near-surface geology and site response improve when one has more robust estimates of site response? Does long-period basin response exhibit less variability than amplification at higher frequencies?

The database used in our investigation consists of a compilation of factors from both horizontal components at 158 stations, each of which has recorded from five to more than one hundred earthquakes (for most stations, at least 40) between 1997 and 2003. The overwhelming majority of earthquakes analyzed are relatively small, so our results will pertain only to weak motions. Table 1 includes the number of earthquakes that were used in the regression for each station. A declustered catalog was used in the final regression to avoid undue influence from any one source zone. The observations presented in this paper are considered a preliminary "first cut", as the quantity and quality of TriNet data will continue to improve. The results presented here were compared to earlier regression results using a larger but not declustered cata$\log$, however, and no significant changes were found.

Amplification factors were estimated at a total of 57 of the 62 sites listed in Table 1. We estimate average amplification factors relative to station PAS using the east-west component. Plotting these values on the Wills et al. (2000) site characterization map, we find a good (apparent) correlation between amplification values and site condition (Figure 1). A visual inspection of these figures further suggests a basindepth effect, as suggested and/or inferred in previous studies (Field, 2000; Joyner, 2000).

To explore the degree of correlation further we compare the estimated amplification factors with Vs30 values appropriate for the site classes. Following Boore et al. (1997), we estimate representative Vs30 values for the traditional NEHRP classes from the geometric mean of the range for that class, and for the intermediate site classes we use the Vs30 values adopted by Field (2000). Our estimated values are shown in Table 1. We first consider the correlation when one uses the map-based site values. This exercise is intended to illustrate something of a worst-case scenario in siteresponse investigations: considering the correlation between estimated site response and near-surface geology in cases where the geology is known only from large-scale maps and/ or Vs30 is only a representative value for each site class. This exercise reveals a reasonable degree of correlation, in keeping 


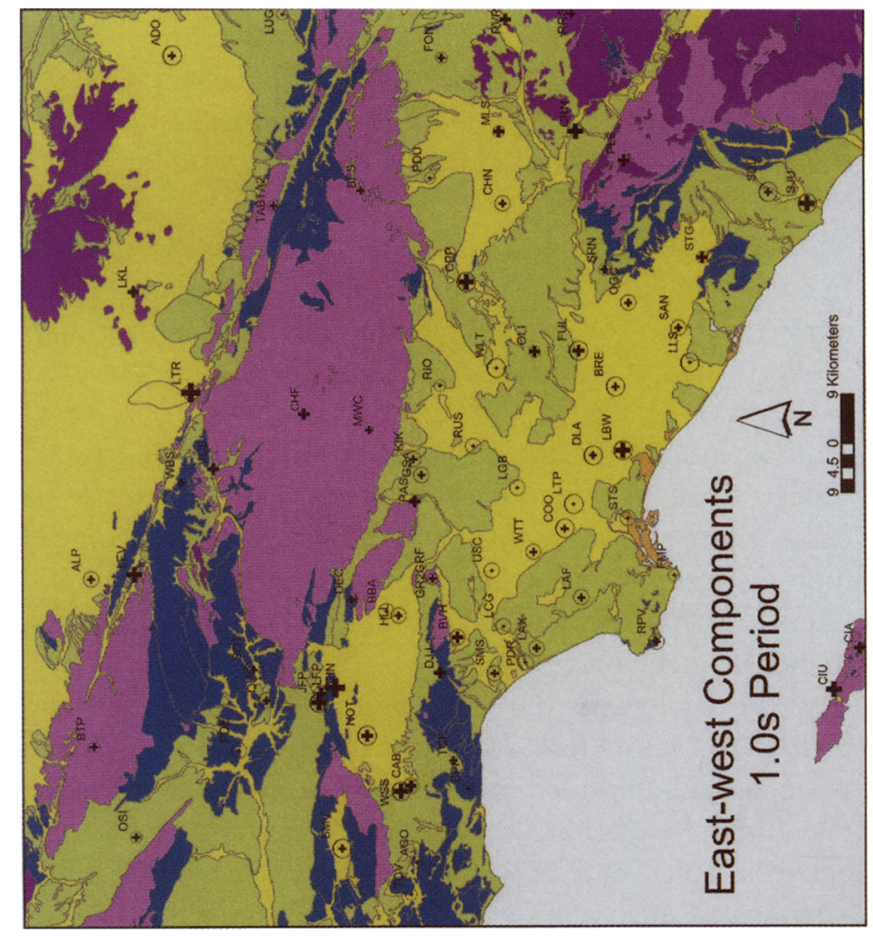

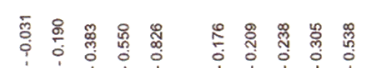

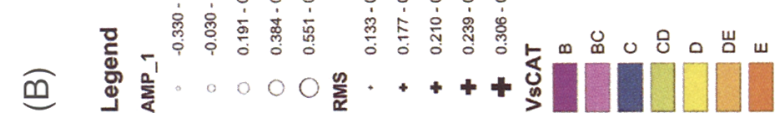
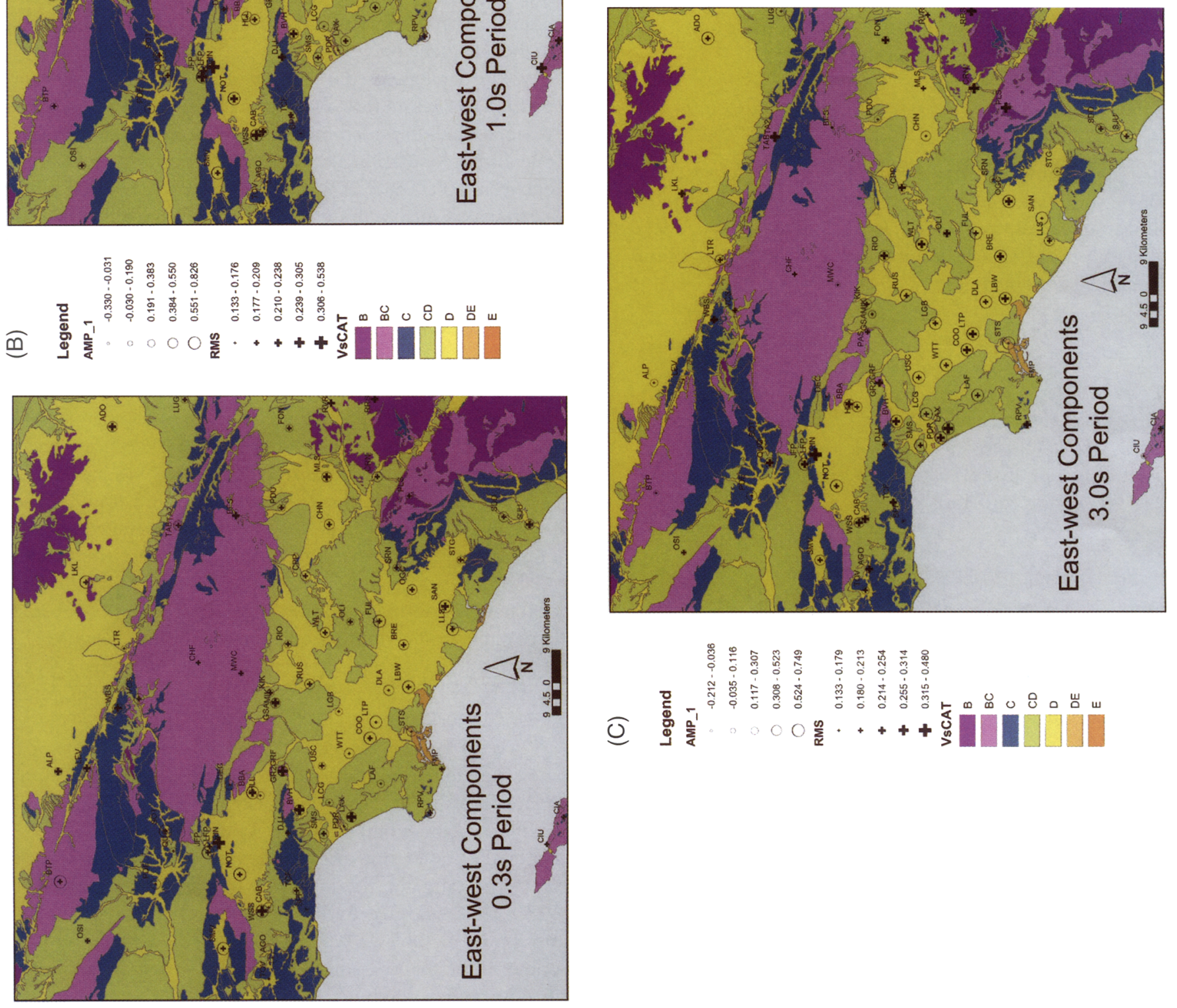

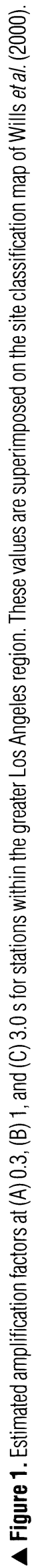

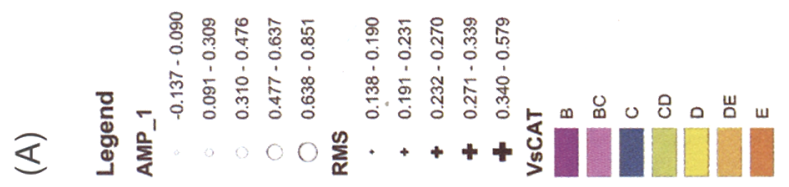



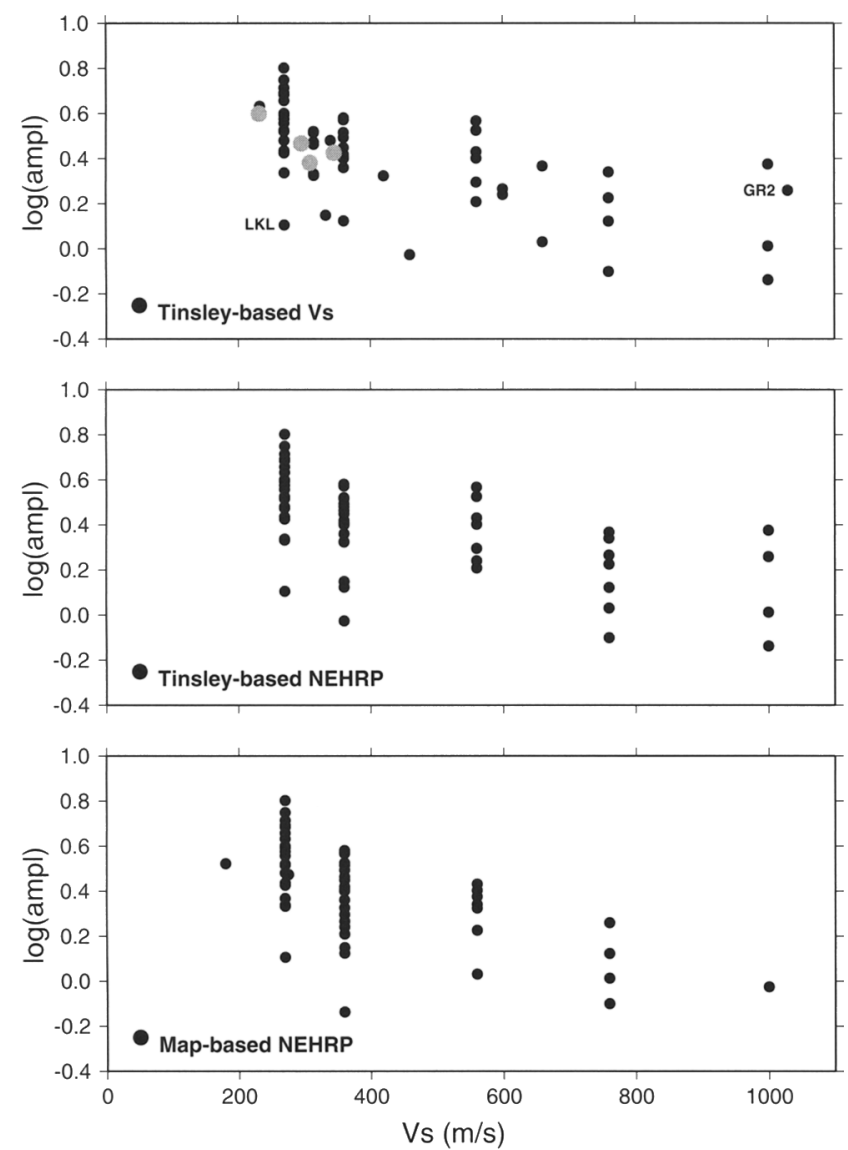

$\Delta$ Figure 2. Estimated amplification factors are shown for the subset of 58 stations in the greater Los Angeles region for which improved site classes have been obtained. Bottom panel shows map-based site class versus 1-s amplification factors from the east-west component (site class is represented by average Vs30 value); middle panel shows site class based on geologic assessments and available drilling data; top panel includes calculated and estimated site-specific Vs30 values, where available (large gray circles indicate CPT results).

with expectations (Boore $e$ al., 1994). Also as expected, there is a high degree of scatter which includes substantial outliers (Figures 2 and 3, bottom panels).

Focusing on the subset of stations in the greater Los Angeles region, for which site classifications have already been assigned based on a general geologic assessment, one is left with observations from 52 stations. We find that the correlation between amplification factors and site condition appears to be improved using the corrected factors (Figures 2 and 3, middle panels). If we further refine Vs30 estimates at those sites where one could be assigned based on prior knowledge of particular geologic units, the correlation appears to improve somewhat. The scatter is still large (Figures 2 and 3, top panels), however. In fact, fitting a straight line through the results shown in each of the panels in Figure 3, the rms misfit of the top panel (the best velocity estimates) is only about $2 \%$ lower than that of the bottom panel.

Several further refinements may be required to reduce the misfit more substantially. One refinement would be a
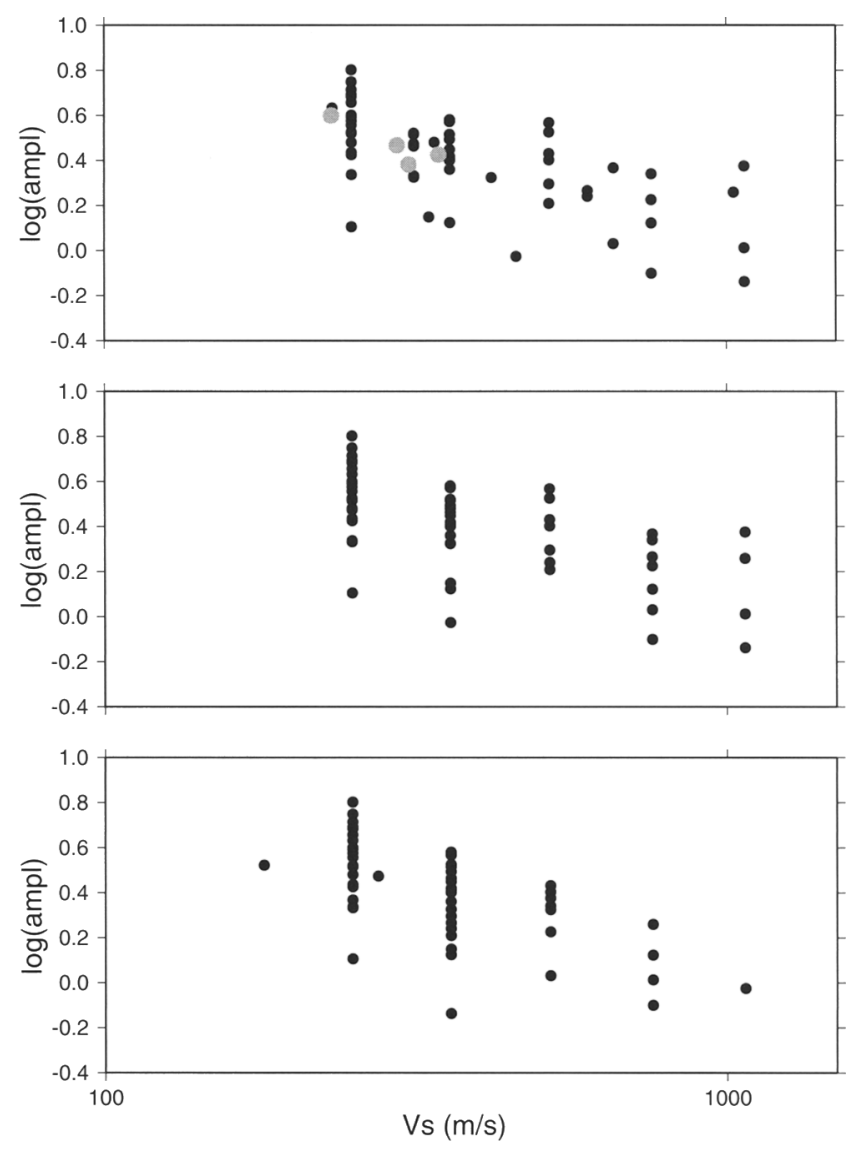

$\Delta$ Figure 3. Same data and panels as shown in Figure 2 but with Vs30 plotted on a logarithmic axis.

more careful evaluation of the stations that are outliers in the top panel of Figure 3, including stations LKL and GR2. LKL is known to be a site where the Holocene alluvium is thin, and where Vs30 is very likely much higher than that of a NEHRP D site. Tinsley estimated B-BC rock conditions at a depth of less than $15 \mathrm{~m}$ but did not consider the available information sufficient to estimate a Vs30 value for the site. The site therefore remains classified as $\mathrm{D}$ because this is considered the appropriate classification for the near-surface material. Not surprisingly, the site does not exhibit correspondingly strong amplifications, especially at longer periods. One of the other outliers, station GR2, is on Griffith Peak in the Santa Monica Mountains. This site has been used in seismic investigations prior to the TriNet project and had previously been observed to have relatively high amplification for a rock site (Rogers et al., 1984). It is possible that amplification at this location is caused by topographic effects, which have been observed in previous studies (e.g., Boore, 1973) and can be predicted from theory (e.g., Sanchez-Sesma and Campillo, 1991). A future goal of our investigations will be to explore this possibility.

One of the long-term goals of our project is to use the wealth of data recorded by the TriNet stations to further explore open issues regarding site and basin response, as well as topographic effects. As a preliminary observation, we con- 

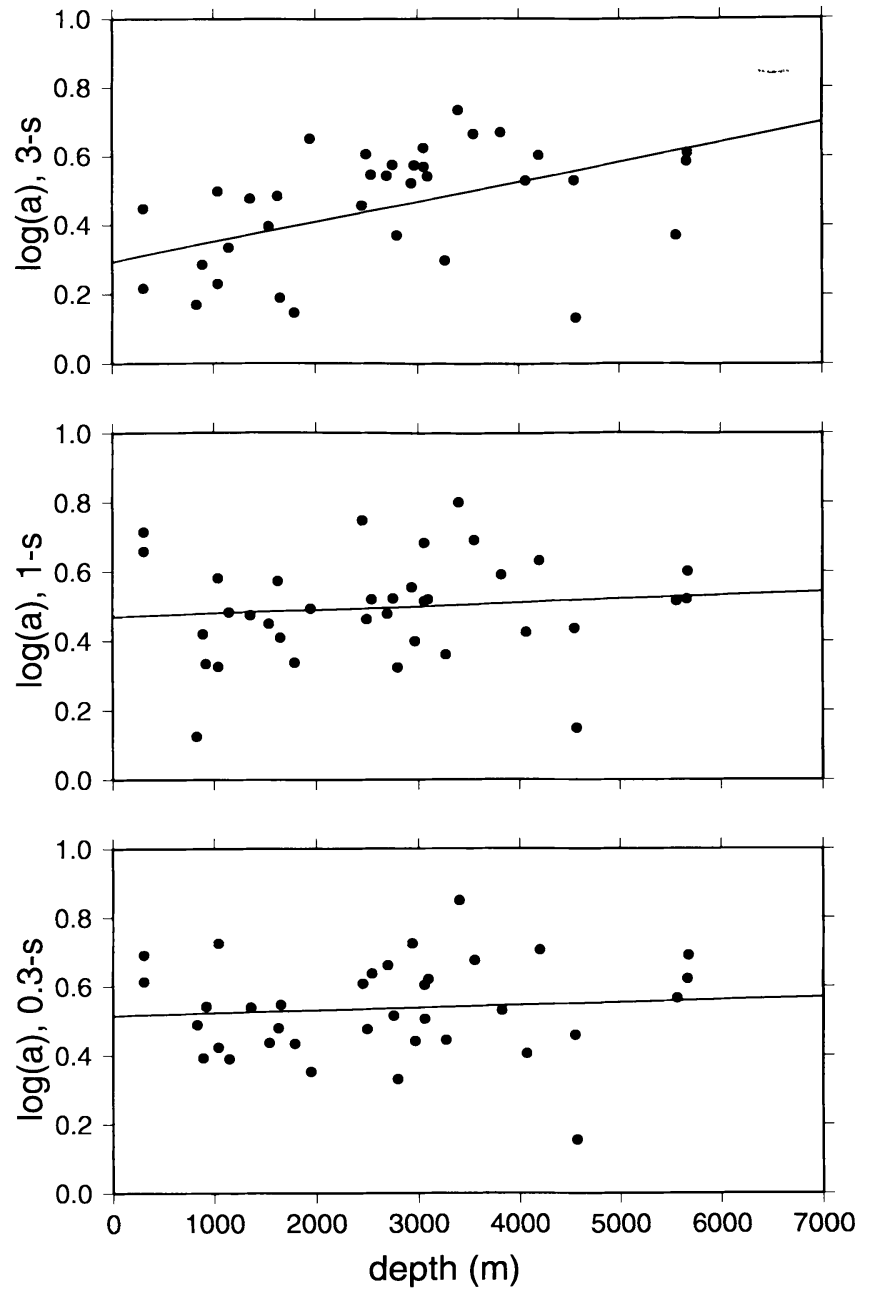

$\Delta$ Figure 4. Amplification factors at $0.3,1$, and $3 \mathrm{~s}$ are shown in the bottom, middle, and top panels, respectively, as functions of basin depth. Least-squares linear regressions through these data yield the lines shown in each panel.

clude that the data do reveal evidence of a basin-depth effect, which has been inferred in previous studies. Assuming that basin depth corresponds to the depth of the $2.5 \mathrm{~km} / \mathrm{s}$ shearwave velocity level as defined by the model of Magistrale (2000), we find a correlation between basin depth and average 3-s amplification factor (Figure 4). (The choice of the $2.5 \mathrm{~km} / \mathrm{s}$ contour is somewhat arbitrary; using a different value would primarily "stretch" or compress the $x$ axis in Figure 4). To isolate the effect of basin depth we use only stations with estimated Vs30 values below $450 \mathrm{~m} / \mathrm{s}$. As expected, the correlation appears to be stronger for longer-period amplification factors; only a weak signal is apparent in the 0.3-s and $1.0-\mathrm{s}$ residuals. Least-squares linear regressions through the data shown in Figure 4 yield the lines shown in each panel; these are presented only for illustration, as there is no reason to expect that the variables will have a linear relationship: Field (2000) estimated a factor of 2 change in amplification factor between stations in the deepest part of the Los Angeles basin and stations at the edges of the basin. Our results are consistent with these results.

\section{DISCUSSIONS AND CONCLUSIONS}

After canvassing and compiling information for the initial set of 62 TriNet sites, our results indicated that there were several field settings where the Wills et al. (2000) approach tended to result in an incorrect determination of the site class. We note that this does not indicate any sort of failure of the map per $s e$, but rather the inappropriate use of it. Specific determinations of site condition based on a map of this scale $(1: 250,000)$ is expected to have an "error" rate of at least $25 \%$. That is, map-based site assignments are expected to yield erroneous classifications for one out of every four stations. This rate may be even higher for seismic stations, which can be selected specifically because they are "pathological." For example, seismometers are sometimes sited on small, isolated hard-rock outcrops. One example is station OSI: a CD site according to the map-based classification, but in fact situated on fairly competent rock within a tunnel.

Indeed, we encountered situations where a site was located on or near a geologic contact and the proper geologic map unit to assign to the instrument site was ambiguous or had been incorrectly selected. A second problem situation is sites where the alluvium is thin or patchy and overlies crystalline bedrock. If bedrock areas were too small to be mapped, a station could appear to be sited on alluvium when it was in fact on bedrock. A third situation involved sites at which the geologic units were apparently correctly mapped and were appropriate for the locations of the stations, but where local conditions such as degree of cementation or consolidation were atypical of the geologic units. In all these instances, familiarity with local geology relative to likely Vs30 or site classification is an essential prerequisite for identification of problems and selection of the appropriate site classification.

We encountered some field situations that may be of research interest for scientists who analyze TriNet data. For example, station FMP in San Pedro appears to be attached to the reinforced concrete roof of a former Nike-missile bunker. This instrument is presumably well anchored to ground or a floor of some sort; the question is, what is this ground anchored to? To the degree that TriNet installations are intended to be free-field instruments, the likely soil-structure interactions at these installations mean that these stations' records should be scrutinized with care, especially at shorter periods, for evidence of soil-structure interactions.

Aside from such special cases, our preliminary field investigations have been promising, suggesting that improved geologic site information can improve our ability to understand, and ultimately predict, site and/or basin response. The investigation of empirical site response factors, and analysis of their correlation with near-surface geology, has been an area of active research in ground-motion seismology for many decades. Although basic physical principles predict that ground motions will be strongly controlled by the near-sur- 
face shear-wave velocity structure at any site, this effect will be complicated by a number of other effects. Among other issues, there will clearly be limitations associated with the use of a single value to quantify "near surface" velocity. The commonly used value of Vs 30 might not be the optimal variable to use, but it is the variable that, at present, is most likely to be available and/or obtainable.

Many studies have inferred a correlation between site response and near-surface geology, but with a very high degree of scatter. Recently, Field (2000) demonstrated that the correlation could be improved with the incorporation of intermediate NEHRP site classes. This result highlights an important general point: All site-response investigations will be hampered by uncertainties in both the observed siteresponse estimates and the shear-wave velocity values.

The TriNet project represents a unique opportunity to investigate the degree to which site-specific ground motions can be better predicted by reducing both types of uncertainties. The data will also be of substantial value for the investigation of remaining research issues in site and basin response, including further quantification of the basin-depth effect (Field, 2000; Joyner, 2000) and nonlinearity.

Site amplification results such as those presented in this study can also be used to explore the possibility that basin response and topographic effects depend in a systematic way on source location. Both ground-motion modeling studies, such as the work by Olsen (2000), and previous observational studies (e.g., Hough et al., 1995; Hartzell et al., 2003) reveal that earthquakes in different locations-and/or with different rupture parameters-will cause markedly different responses in three-dimensional basins and valleys. One could similarly investigate topographic effects by looking at the azimuthal distribution of residuals at sites where such effects might be expected. Such investigations require large data sets with good azimuthal distribution of events at each station, a requirement that has not generally been met in past siteresponse studies but is potentially met in this case. The data set discussed in this report was relatively large, but the quantity and quality of TriNet data will only continue to increase in the future.

In just its first few years of operation the network has recorded an enormous volume of high-quality, broadband data that have been used to estimate site amplifications with anywhere from a dozen to $100+$ earthquakes per site. The ongoing site characterization task, described in this note, has taken the first steps to improve our estimates of key geotechnical variables at each site; results to date are preliminary but promising.

Our project will face challenges over the new few years: to develop a database that will be both of maximum utility to a broad user community, and yet flexible enough to handle whatever site characterization results we obtain in the future; and to develop and implement effective strategies to measure geotechnical variables at sites with a wide range of geologic conditions and cultural settings. We welcome the community's feedback on either or both of these issues.

\section{ACKNOWLEDGMENTS}

We thank David Boore, Norm Abrahamson, and Jack Boatwright for helpful comments and reviews of this manuscript. We are further indebted to Chris Cramer and Paul Bodin for careful and constructive reviews. This research was supported by the Southern California Earthquake Center. SCEC is funded by NSF Cooperative Agreement EAR-8920136 and USGS Cooperative Agreements 14-08-0001-A0899 and 02HQAG0008. The SCEC contribution number for this paper is 774 .

\section{REFERENCES}

Anderson, J. G. and S. E. Hough (1984). A model for the shape of the Fourier amplitude spectrum of acceleration at high frequencies, Bulletin of the Seismological Society of America 74, 1,969-1,994.

Boore, D. M. (1973). Effect of simple topography on seismic waves: Implications for accelerations recorded at Pacoima Dam, San Fernando Valley, California, Bulletin of the Seismological Society of America 63, 1,603-1,609.

Boore, D. M., W. B. Joyner, and T. E. Fumal (1997). Equations for estimating horizontal response spectra and peak acceleration from western North American earthquakes: A summary of recent work, Seismological Research Letters 68, 128-153.

Drake, D. (1815). Natural and Statistical View, or Picture of Cincinnati and the Miami County, Illustrated by Maps, Cincinnati: Looker and Wallace.

Field, E. H. (2000). A modified ground-motion attenuation relationship for southern California that accounts for detailed site classification and a basin-depth effect, Bulletin of the Seismological Society of America 90, S209-S221.

Frankel, A., S. Hough, P. Friberg, and R. Busby (1991). Observations of Loma Prieta aftershocks from a dense array in Sunnyvale, California, Bulletin of the Seismological Society of America 81, $1,900-1,922$.

Gibbs, J. F., J. C. Tinsley, D. M. Boore, and W. B. Joyner (1999). Seismic velocities and geological conditions at twelve sites subjected to strong ground motion in the 1994 Northridge, California earthquake: A revision of OFR 96-740, U.S. Geological Survey OpenFile Report, OF 99-446.

Gibbs, J. F., J. C. Tinsley, D. M. Boore, and W. B. Joyner (2000). Borehole velocity measurements and geologic conditions at thirteen sites in the Los Angeles, California region, U.S. Geological Survey Open-File Report, OF 00-470.

Hartzell, S., D. Carver, R. A. Williams, S. Harmsen, and A. Zerva (2003). Site response, shallow shear-wave velocity, and wave propagation at the San Jose, California, dense seismic array, Bulletin of the Seismological Society of America 93, 443-464.

Hartzell, S., S. Harmsen, A. Frankel, D. Carver, E. Cranswick, M. Meremonte, and J. Michael (1998). First-generation site response maps for the Los Angeles region based on earthquake ground motions, Bulletin of the Seismological Society of America 88, $463-472$.

Heaton, T., R. Clayton, J. Davis, E. Hauksson, L. Jones, H. Kanamori, J. Mori, R. Porcella, and T. Shakal (1996). The TriNet project, Proceedings of 11 th World Conference on Earthquake Engineering, Paper No. 2136, Acapulco, Mexico.

Heuze, F., C. Alex, R. Archuleta, F. Bonilla, E. Cochran, S. Day, M. Doroudian, A. Elgamal, S. Elrick, G. Ely, R. Funk, S. Gonzales, L. Gurrola, M. Hoehler, T. Lai, D. Lavallee, B. Lawrence, P-C Liu, A. Martin, L. Matesic, R. Mellors, B. Minster, C. Nicholson, D. Oglesby, S. Park, M. Rimer, J. Steidl, T. Tyler, F. Vernon, M. Vucetic, J. Wagoner, and Z. Yang (2003). Estimating site-specific 
strong earthquakes motions, The University of California's campus earthquake program, Soil Dynamics and Earthquake Engineering (submitted).

Ho-Liu, P., H. Kanamori, and R.W. Clayton (1988). Application of attenuation tomography to Imperial Valley and Coso-Indian Wells region, Southern California, Journal of Geophysical Research 93, $10,501-10,520$.

Hough, S. E., C. Dietel, G. Glassmoyer, and E. Sembera (1995). On the variability of aftershock ground motions in the San Fernando Valley, Geophysical Research Letters 22, 727-730.

Joyner, W. B. (2000). Strong motion from surface waves in deep sedimentary basins, Bulletin of the Seismological Society of America $\mathbf{9 0}$, S95-S112.

Kanamori, H., J. Mori, E. Hauksson, T. H. Heaton, L. K. Hutton, and L. M. Jones (1993). Determination of earthquake energy release and M(L) using TERRAscope, Bulletin of the Seismological Society of America 83, 330-346.

Magistrale, H., S. Day, R. W. Clayton, and R. Graves (2000). The SCEC Southern California reference three-dimensional seismic velocity model Version 2, Bulletin of the Seismological Society of America 90, S65-S76.

Olsen, K. B. (2000). Site amplification in the Los Angeles Basin from three-dimensional modeling of ground motion, Bulletin of the Seismological Society of America 90, S77-S94.

Rogers, A. M., R. D. Borcherdt, P. A. Covington, and D. M. Perkins (1984). A comparative ground response study near Los Angeles using recordings of Nevada nuclear tests and the 1971 San Fernando earthquake, Bulletin of the Seismological Society of America 74, 1,925-1,950.

Sanchez-Sesma, F. J. and M. Campillo (1991). Diffraction of P, SV, and Rayleigh waves by topographic features: A boundary integral formulation, Bulletin of the Seismological Society of America 81, $2,234-2,253$.
Wald, L. A. and J. Mori (2000). Evaluation of methods for estimating linear site response amplifications in the Los Angeles region, Bulletin of the Seismological Society of America 90, S32-S42.

Wessel, P. and W. H. F. Smith (1991). Free software helps map and display data, Eos, Transactions of the American Geophysical Union 72, $441-446$.

Wills, C. J., M. Petersen, W. A. Bryant, M. Reichle, G. A. Saucedo, S. Tan, G. Taylor, and J. Treiman (2000). A site-conditions map for California based on geology and shear-wave velocity, Bulletin of the Seismological Society of America 90, S187-S208.

U.S. Geological Survey 345 Middlefield Road Menlo Park, CA 94025

(J.T.)

U.S. Geological Survey 525 S. Wilson Avenue Pasadena, CA 91106 hough@gps.caltech.edu (S.E.H., A.Y.)

California Institute of Technology Pasadena, CA (H.K., E.Y., V.A.)

California Geological Survey Sacramento, $C A$

(C.W.) 